\title{
REVIEW
}

\section{Diets involved in PPAR and PI3K/AKT/PTEN pathway may contribute to neuroprotection in a traumatic brain injury}

Yasuko Kitagishi ${ }^{\dagger}$ and Satoru Matsuda*†

\begin{abstract}
Traumatic encephalopathy has emerged as a significant public health problem. It is believed that traumatic encephalopathy is caused by exposure to repetitive brain trauma prior to the initial symptoms of neurodegenerative disease. Therefore, prevention is important for the disease. The PI3K/AKT/PTEN (phosphoinositide-3 kinase/AKT/phosphatase and tensin homologue deleted on chromosome 10) pathway has been shown to play a pivotal role in neuroprotection, enhancing cell survival by stimulating cell proliferation and inhibiting apoptosis. PTEN negatively regulates the PI3K/AKT pathways through its lipid phosphatase activity. Although PTEN has been discovered as a tumor suppressor, PTEN is also involved in several other diseases, including diabetes and Alzheimer's disease. Dietary fish oil rich in polyunsaturated fatty acids may induce the PTEN expression by activation of peroxisome proliferator-activated receptor. Supplementation of these natural compounds may provide a new therapeutic approach to the brain disorder. We review recent studies on the features of several diets and the signaling pathways involved in traumatic encephalopathy.
\end{abstract}

\section{Introduction}

Traumatic brain injury is a major health problem throughout the world and is a leading cause of mortality and disability $[1,2]$. The consequent encephalopathy is a complicated pathological process; however, the main cause of the deleterious cascades may be cell damage in mitochondria at the cellular level [3]. Reactive oxygen species (ROS), caspases, and apoptosis may be the main participants in the mitochondrial cell damage. Traumatic brain injury is associated with permanent spatial learning dysfunction and motor deficits due to brain damage [4]. No pharmacological therapies have yet been approved for the treatment of traumatic brain injury. The possibility of an effective treatment could be based on the fact that the majority of traumatic neurodegeneration is due to a pathophysiological cascade after the injury that exacerbates the damaging effects of the injury. One of the validated mechanisms revealed in experimental traumatic brain injury involves oxygen radical-induced oxidative damage to lipids, proteins, and nucleic acids [3,5].

\footnotetext{
* Correspondence: smatsuda@cc.nara-wu.ac.jp

${ }^{\dagger}$ Equal contributors

Department of Food Science and Nutrition, Nara Women's University, Kita-Uoya Nishimachi, Nara 630-8506, Japan
}

Developing new therapies for traumatic brain injury requires elucidation of the neuroprotective mechanisms [5]. The ROS are generated during mitochondrial oxidative metabolism as well as in cellular response to pathogens, which act as signaling molecules and regulate various physiological processes, including proliferation, differentiation, apoptosis, and migration [6-8]. In addition, protein and lipid oxidation by ROS is proposed as a crucial determinant of brain health. Nicotinamide adenine dinucleotide phosphate (NADPH) oxidase is a complex that produces ROS during the ischemic period, which is also a major source of endogenous ROS that comes from mitochondria during the process of oxidative phosphorylation to produce energy in the form of ATP [9]. NADPH oxidase-generated ROS are also implicated in the development of angiotensin II-dependent hypertension mediated through the hypothalamic neurons [10]. In addition, ROS are produced by intracellular membrane oxidases. Inflammation is a source of ROS at the sites of tissue. It is important for cells to neutralize ROS before they can damage cellular macromolecules. One mechanism by which ROS are thought to exert their effects is through the reversible regulation of target molecules such as 
protein kinase $C$, mitogen-activated protein kinase, phosphoinositide-3 kinase (PI3K), tyrosine phosphatase, and phosphatase and tensin homolog deleted on chromosome 10 (PTEN) [11]. However, less is known about the initial regulation of signaling molecules by ROS. Cellular ROS metabolism is tightly regulated by a variety of proteins involved in the redox mechanism.

Traumatic brain injury is a devastating neurological injury associated with significant morbidity and mortality. The prevention of brain dysfunction in traumatic encephalopathy is a public health concern because of a lack of effective treatments. Several potential preventive factors, including modifiable lifestyle factors such as diet, have been suggested by epidemiological research [12]. It has been demonstrated that dietary choices can play a key role in the neuroprotection of traumatic encephalopathy [12]. However, the epidemiological analysis of the relations between nutrient consumption and neroprotection is complex, and it is unlikely that a single component plays a major role. The complexity of human diet, especially the high synergistic or antagonistic correlation among the effects of various nutrients and foods, makes it difficult to examine their distinct effects. Because many factors in life influence brain function, several interventions might be promising in the prevention of brain dysfunction in traumatic encephalopathy. The main objective of this article is to review the studies linking potential protective factors to pathogenesis of traumatic encephalopathy, focusing on the roles of polyunsaturated omega-3 fatty acids (PUFAs) and curcumin in the PI3K/AKT/ PTEN pathway. We will summarize the current research into mechanisms by which several diet factors bind to the interaction partners to transduce signals downstream and the implications for the disease-associated biology.

\section{Reactive oxygen species involved in the PI3K/AKT/PTEN pathway and in neuronal disorder}

Studies indicate that prevention of traumatic brain injury-induced ROS production decreases blood-brain barrier disruption, neuronal death, and microglial activation, which may have high therapeutic potential to reduce traumatic brain injury-induced neuronal death [13]. In addition, a number of studies have demonstrated an antioxidant role for tumor-suppressor proteins, activating the expression of some antioxidant genes in response to oxidative stress. Tumor-suppressor genes regulate diverse cellular activities, including DNA damage repair, cell cycle arrest, cell proliferation, cell differentiation, migration, and apoptosis [14]. PTEN is a tumor-suppressor gene that is frequently deleted or mutated in a variety of human cancers. It has been demonstrated that upregulation of PTEN causes modulation of PI3K/AKT signaling to reduce ROS generation in cells [15]. Phosphatidylinositol 3,4,5-triphosphate (PIP3) is the major second messenger of the PI3K pathway that mediates receptor tyrosine kinase signaling to the survival kinase AKT. PTEN negatively regulates the activity of PI3K/AKT signaling by converting PIP3 to PIP2 (phosphatidylinositol 4,5-bisphosphate). Increased levels of PIP3 at the membrane cause PH domain-containing proteins such as AKT to co-localize, resulting in the kinase-mediated phosphorylation and activation [16]. The activated AKT phosphorylates target proteins involved in cell survival, cell cycling, angiogenesis, and metabolism for neuroprotection (Figure 1). A role for PI3K/ AKT signaling in synaptic scaling is suggested by the findings that inhibition of PI3K blocks homeostatic AMPA $(\alpha$-amino-3-hydroxy-5-methyl-4-isoxazolepropionic acid) receptor delivery to synapses [17]. A clear dissociation between AKT and ribosomal S6K signaling markers could be involved in the brain pathological process [18]. The phosphorylation of presenilin 1 (PS1) downregulates its cellsurface expression, which leads to an impaired activation of the PI3K/AKT cell survival signaling. The PS1 also regulates induction of hypoxia-inducible factor- $1 \alpha$ [19]. Accordingly, the abnormal activation of glycogen synthase kinase-3-beta (GSK3 $\beta$ ) can reduce neuronal viability [20]. In other words, selective downregulation of the AKT concurrent with elevated GSK3 $\beta$ activity may be linked to brain dysfunctional pathogenesis [21]. Recently, it has been shown that AKT activation may play a therapeutic role in neurodegenerative diseases $[22,23]$.

The tumor suppressor PTEN, which antagonizes the PI3K/AKT pathway, has been recognized to play a key role in neural functions. Its level has been found to be reduced in Alzheimer's disease (AD) brains [23,24]. PTEN negatively regulates the activity of PI3K/AKT signaling by converting PIP3 to PIP2. The PIP3 is the principal second messenger of the PI3K pathway that mediates receptor tyrosine kinase signaling to the survival kinase AKT. Increased levels of PIP3 at the membrane cause PH domaincontaining proteins such as AKT and PDK- 1 to co-localize, resulting in the kinase-mediated phosphorylation and activation [16]. Schematic structures of the AKT and PTEN protein are shown in Figure 2. The activated AKT phosphorylates target proteins involved in cell survival, cell cycling, and metabolism. Cell cycle mediators affected by AKT and PTEN include the forkhead transcription factors and GSK3 $[25,26]$. PTEN acts as a regulator of maintaining basal levels of PIP3 below a threshold for those signaling activation. PTEN also plays an important role in the induction of apoptotic cell death signals in cells when cells lose contact with the extracellular matrix [27]. Presenilins may play an important role in signaling pathways involving PI3K/AKT and PTEN that are crucial for physiological functions and the pathogenesis of AD [28]. PTEN may also be involved in a disease state such as Parkinson's disease [29]. 


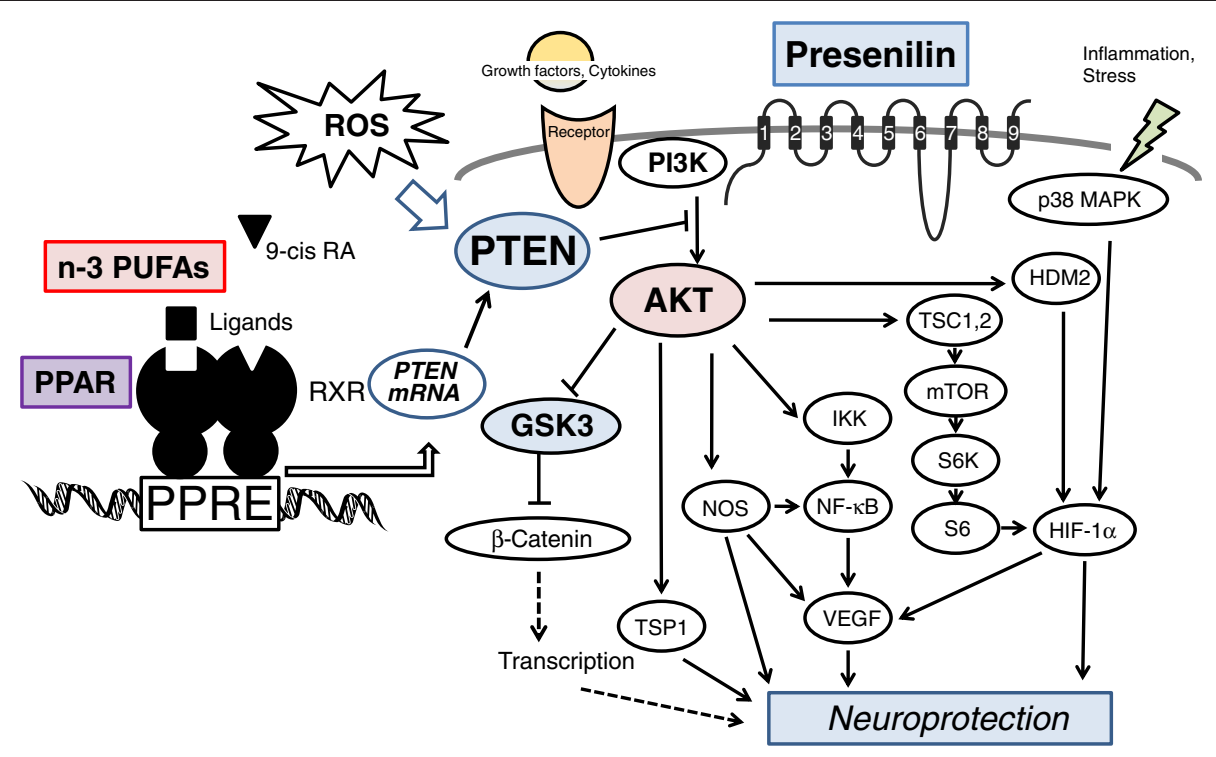

Figure 1 Schematic representation and overview of PTEN/PI3K/AKT signaling and a model of the mechanism of peroxisome proliferator-activated receptor (PPAR) action. Similar to other nuclear hormone receptors, PPARs act as a ligand-activated transcription factor. PPARs, in response to ligand binding, hetero-dimerize with retinoid-X-receptor (RXR) and bind PPAR response element (PPRE) DNA sequences in the promoters of target genes, including PTEN. The uncontrolled generation of reactive oxygen species (ROS) might contribute to cell proliferation by inhibiting PTEN function. Examples of molecules known to act on the PTEN/PI3K/AKT regulatory pathways are also shown; these molecules may relate to the function of presenilin. Hammerheads mean inhibition. Some critical pathways have been omitted for clarity. GSK3, glycogen synthase kinase-3; HDM2, human homologue of murine mdm2; HIF-1a, hypoxia-inducible factor-1a; IKK, IKB kinase; MAPK, mitogenactivated protein kinase; mTOR, mammalian target of rapamycin; NF-KB, nuclear factor-kappa-B; NOS, nitric oxide synthase; PI3K, phosphoinositide3 kinase; PTEN, phosphatase and tensin homologue deleted on chromosome 10; PUFA, polyunsaturated fatty acid; RA, retinoic acid; TSC, tuberous sclerosis complex; TSP1, thrombospondin 1; VEGF, vascular endothelial growth factor.

Potential therapeutic approach for cellular protection via the modulation of PI3K/AKT/PTEN pathway

A wide variety of compounds have been identified as peroxisome proliferator-activated receptor (PPAR) ligands. The n-3 PUFAs have a beneficial effect on most of the metabolic risk factors by regulating gene transcription factors, including PPAR $\alpha$ and PPAR $\gamma$ [30]. Treating cells with the insulin-sensitizing drug pioglitazone, a PPAR $\gamma$ agonist, attenuates the ROS signaling pathway [31]. Correcting insulin signal dysregulation in traumatic brain injury may also offer a potential therapeutic approach. A schematic protein structure of the PPARs is shown in Figure 2. Ligand-activated PPARs bind as heterodimers with the retinoid X receptor (RXR) on PPAR response elements, which are present in the promoter regions of the responsive genes [32] (Figure 1). Retinoic acid also affects a broad spectrum of physiological processes, including cell growth, differentiation, morphogenesis, reproduction, and development [33], through the action of two types of receptors: the retinoic acid receptors (RARs) and the RXRs. The transcriptional control by the PPAR/RXR heterodimer also requires interaction with co-regulator complexes [34]. Thus, selective action of PPARs in vivo results from the interplay at a time point of each of the co-factors available. A number of PPAR target genes have been characterized. Combined treatment with agonists for the heterodimeric binding partners of PPAR $\gamma$ and the RXRs shows additive enhancement of the amyloid-beta $(\mathrm{A} \beta)$ uptake that is mediated by $\mathrm{RXR} \alpha$ activation [35]. Simultaneous activation of the PPAR $\gamma /$ $\mathrm{RXR} \alpha$ heterodimer may prove beneficial in prevention of traumatic brain injury. Furthermore, PPAR $\gamma$ represents a signaling system that can intercede to restore neural networks [36]. It has been reported that oral administration of the RXR agonist, bexarotene, to a mouse model of $\mathrm{AD}$ results in enhanced clearance of soluble A $\beta$ [37]. Furthermore, bexarotene stimulated the rapid reversal of cognitive deficits and improved neural circuit function. Accordingly, RXR activation may stimulate physiological $A \beta$ clearance mechanisms.

Activated PPARs upregulate expression of PTEN (Figure 1). Type-2 diabetes is characterized by diminished pancreatic $\beta$-cell function. Insulin signaling within the $\beta$-cells has been shown to play an important role in maintaining the function of the $\beta$-cells. Under basal conditions, enhanced insulin-PI3K signaling via deletion of PTEN leads to increased $\beta$-cell mass [38]. Mice with PTEN deletion in pancreatic cells show an increase in the $\beta$-cell mass because of both increased proliferation and reduced apoptosis. In particular, the 


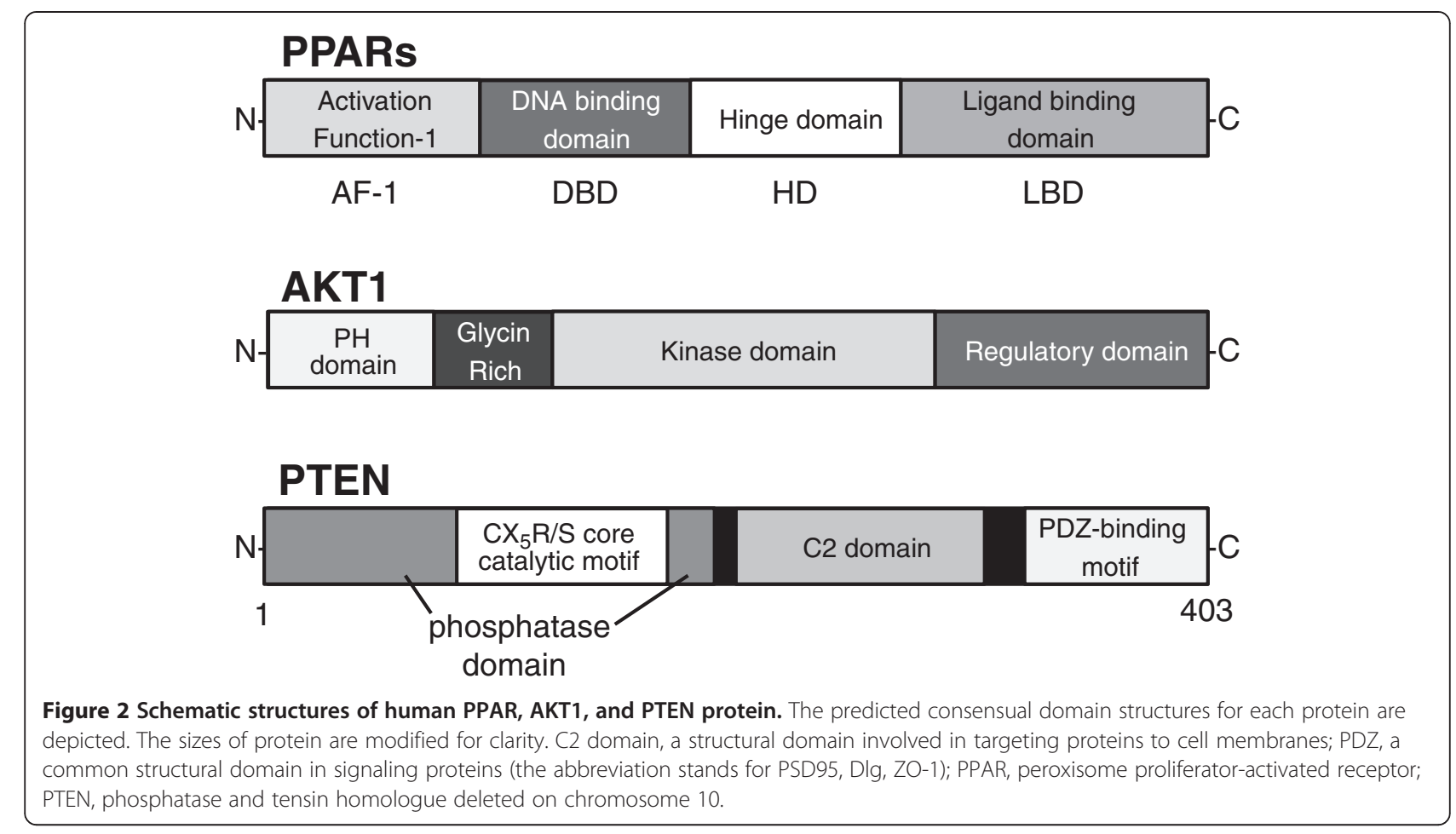

relationship between PTEN function and adipocytespecific fatty acid-binding protein FABP4 is of interest in $\beta$-cell signaling [39]. The interaction of PTEN to FABP4 suggests a role for this phosphatase in the regulation of lipid metabolism and cell differentiation [40]. Tissue-targeted deletion of PTEN leads to improved insulin sensitivity in the insulin-responsive tissues and protects from diabetes [41]. On the other hand, ligands of PPARs are used as oral anti-diabetics [42]. The PTEN is ubiquitously expressed throughout early embryogenesis in mammals [43]. Interestingly, rosemary extract represses PTEN expression in K562 leukemic culture cells [44]. The schematic structure of the PTEN protein is also shown in Figure 2. PTEN protein consists of $\mathrm{N}$-terminal phosphatase, C-terminal C2, and PDZ (PSD-95, DLG1, and ZO-1) binding domains. The PTEN CX5R(S/T) motif resides within an active site that surrounds the catalytic signature with three basic residues, which are critical for PTEN lipid phosphatase activity. The structure endows PTEN with its preference for acidic phospholipid substrates such as PIP3. Neuroprotection by inhibiting PTEN has been reported by activating the anti-apoptotic PI3K/AKT pathway in primary neurons [45-47].

\section{Some diets may contribute to neuroprotective effects}

Curcumin, a component of turmeric, potently lowers $A \beta$ levels in a dose-dependent manner. Furthermore, in vivo studies indicated that curcumin was able to reduce $A \beta$ -

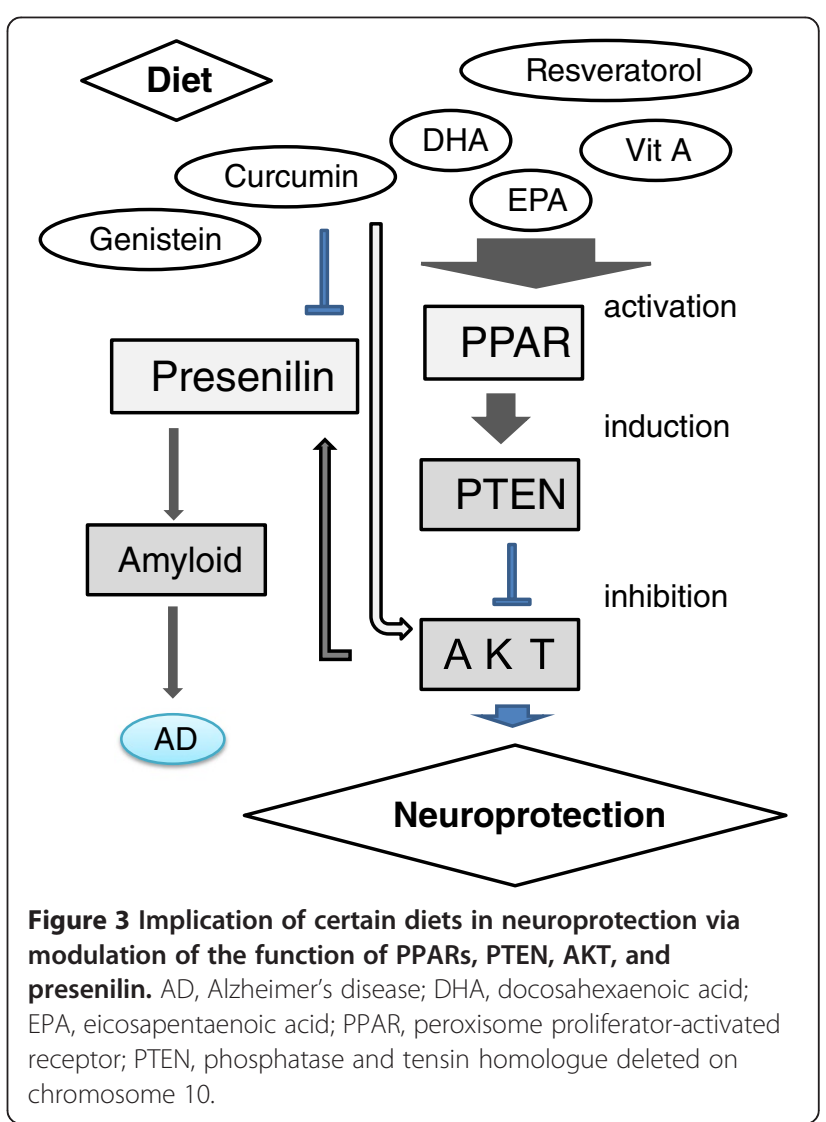


related pathology in mouse models via unknown molecular mechanisms [48]. In addition, curcumin can improve structure and plasticity of synapse and enhance their learning and memory abilities [49]. The protective effect of curcumin is associated with a significant attenuation in the expression of interleukin-1b, a pro-inflammatory cytokine [50]. Curcumin also reverses the induction of aquaporin-4, an astrocytic water channel implicated in the development of cellular edema after brain trauma [50]. Curcumin blocks IL-1b-induced aquaporin-4 expression in cultured astrocytes by reduced activation of the p50 and p65 subunits of nuclear factor-kappa-B. Interestingly, curcumin enhances synaptic plasticity and cognitive function after fluid percussion injury in rats [51], suggesting that curcumin may represent a potent therapeutic agent that exerts multiple beneficial effects after traumatic brain injury. It is suggested that the neuroprotection of curcumin might be mediated via PI3K/AKT signaling pathway [52]. Dietary treatment with curcumin, fish oil, or a combination of both has the potential to improve c-Jun $\mathrm{N}$-terminal kinase signaling, phospho-tau pathology, and cognitive deficits in $\mathrm{AD}$ [53].

Genistein, a phytoestrogen present in high concentrations in soy, also downregulates presenilin via the inhibition of ubiquilin 1 expression in lymphoid cells [54]. Genistein has potent anti-tumor activity in various cancer cells. In addition to the inhibition of tyrosine kinases, genistein has a strong estrogen-like effect, which is also beneficial for the plasticity of AD [55]. Genistein potentiates the anti-cancer effects of gemcitabine in human osteosarcoma via the downregulation of the Akt pathway [56]. Resveratrol also appears to be beneficial as an anti$\mathrm{AD}$ agent [57-60]. Resveratrol treatment also prevented the pro-inflammatory effect of fibrillar $A \beta$ on macrophages by potently inhibiting the effect of $A \beta$ [61]. The n-3 PUFAs are a family of biologically active fatty acids, which have a range of physiological roles that relate to optimal cellular functions. The simplest member of this family, $\alpha$-linolenic acid, can be converted to the biologically more active long-chain n-3 PUFAs such as eicosapentaenoic acid and docosahexaenoic acid. Several works have led to the identification of various PPAR ligands that include the n-3 PUFAs [62,63]. In addition, linoleic acid and $\gamma$-linolenic acid could bind PPAR $\delta$ very well [64]. All distinct PPAR subtypes, PPARs ( $\alpha, \beta$, and $\gamma)$, share a high degree of structural homology with other members of the superfamily in the DNA-binding domain and ligand-binding domain. PPAR-ligands are emerging as potential therapeutics for inflammatory and other metabolic diseases. The use of $n-3$ PUFAs has been shown as a possible preventive measure for AD [65-68]. Retinoic acid affects a variety of physiological processes through the action of RAR and RXR. Stimulation of the RAR $\alpha$ signaling pathway offers therapeutic potential by clearing $A \beta$ for the treatment of AD [69]. Retinoic acid plays a key role in the adult brain by participating in the homeostatic control of synaptic plasticity and is essential for memory function. Retinoids are vitamin A derivatives involved in cellular regulatory processes, including cell differentiation and neurite outgrowth, which may also influence $A \beta$ processing [70]. Thus, neuroprotecton could be performed by certain diets (Figure 3).

\section{Perspective}

Increased ROS can enhance insulin signaling to attenuate the development of insulin resistance. The enhanced ROS-dependent insulin signaling is attributable to the oxidation and inhibition of PTEN. In patients with traumatic brain injury, nutritional status may result in changes in the biochemistry indicators. Curcumin, retinoic acids, and n-3 PUFAs are considered to exert the effects at several cellular levels. In addition, diet usually consists of complex combinations of lipids or nutrients that might act synergistically or antagonistically. One of the pleiotropic properties of these foods could explain their disease-protective potentials, which could be mediated through modulation of PI3K/AKT/PTEN pathway. As PTEN is induced by the activated PPARs, this may also offer a potential therapeutic modality for the treatment of those PTEN-related diseases. These key molecules may be regulated at multiple levels, including transcription, protein stability, and phosphorylation. So, precise understanding of these regulations is crucial for therapeutic intervention and the effective design of novel therapeutics. In addition to showing the antioxidant strategy of scavenging the initiating radicals in the injured brain tissue, recent work has shown that carbonyl scavenging compounds can also act to protect cellular proteins. Further mechanistic studies are needed in order to elucidate the precise molecular mechanisms and to determine whether an adequate dietary intake is related to improved brain function and to determine the role it plays regarding the preservation of brain health. Long-term clinical studies are obligatory to enlighten the effect of treatment in the management of traumatic brain injury.

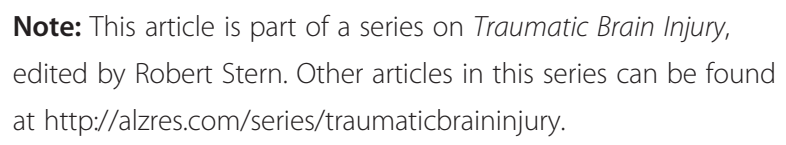

\section{Abbreviations}

AD: Alzheimer's disease; Aß: Amyloid-beta; FABP: Fatty acid-binding protein; GSK3: Glycogen synthase kinase-3; NADPH: Nicotinamide adenine dinucleotide phosphate; PI3K: Phosphoinositide-3 kinase:

PIP2: Phosphatidylinositol 4,5-bisphosphate; PIP3: Phosphatidylinositol 3,4,5triphosphate; PPAR: Peroxisome proliferator-activated receptor; PS1: Presenilin 1; PTEN: Phosphatase and tensin homologue deleted on chromosome 10; PUFA: Polyunsaturated fatty acid; RAR: Retinoic acid receptor; ROS: Reactive oxygen species; RXR: Retinoid-X-receptor. 


\section{Competing interests}

The authors declare that they have no competing interests.

\section{Acknowledgments}

This work was supported by grants-in-aid from the Ministry of Education, Culture, Sports, Science and Technology in Japan. In addition, this work was supported in part by the grant from Nakagawa Masashichi Shoten Co., Ltd.

\section{Published: 26 Sep 2013}

\section{References}

1. Xiong $Y$, Mahmood A, Chopp M: Animal models of traumatic brain injury. Nat Rev Neurosci 2013, 14:128-142.

2. Levin $H$, Smith D: Traumatic brain injury: networks and neuropathology. Lancet Neurol 2013, 12:15-16.

3. Cheng $\mathrm{G}$, Kong RH, Zhang LM, Zhang JN: Mitochondria in traumatic brain injury and mitochondrial-targeted multipotential therapeutic strategies. Br J Pharmacol 2012, 16:699-719.

4. Song SX, Gao JL, Wang KJ, Li R, Tian YX, Wei JQ, Cui JZ: Attenuation of brain edema and spatial learning deficits by the inhibition of NADPH oxidase activity using apocynin following diffuse traumatic brain injury in rats. Mol Med Rep 2012, Oct 24 [Epub ahead of print].

5. Hellmich HL, Rojo DR, Micci MA, Sell SL, Boone DR, Crookshanks JM, DeWitt DS, Masel BE, Prough DS: Pathway analysis reveals common pro-survival mechanisms of metyrapone and carbenoxolone after traumatic brain injury. PLoS One 2013, 8:e53230.

6. Al-Gubory $\mathrm{KH}$, Fowler PA, Garrel C: The roles of cellular reactive oxygen species, oxidative stress and antioxidants in pregnancy outcomes. Int $\mathrm{J}$ Biochem Cell Biol 2010, 42:1634-1650.

7. Zhang Y, Du Y, Le W, Wang K, Kieffer N, Zhang J: Redox control of the survival of healthy and diseased cells. Antioxid Redox Signal 2011, 15:2867-2908

8. Scatena R: Mitochondria and cancer: a growing role in apoptosis, cancer cell metabolism and dedifferentiation. Adv Exp Med Biol 2012, 942:287-308.

9. Ballard JW: Drosophila simulans as a novel model for studying mitochondrial metabolism and aging. Exp Gerontol 2005, 40:763-773

10. Coleman CG, Wang G, Faraco G, Marques Lopes J, Waters EM, Milner TA, ladecola C, Pickel VM: Membrane trafficking of NADPH oxidase p47(phox) in paraventricular hypothalamic neurons parallels local free radical production in angiotensin II slow-pressor hypertension. J Neurosci 2013, 33:4308-4316.

11. Li ZY, Yang Y, Ming M, Liu B: Mitochondrial ROS generation for regulation of autophagic pathways in cancer. Biochem Biophys Res Commun 2011, 414:5-8.

12. Gillette-Guyonnet $S$, Secher M, Vellas B: Nutrition and neurodegeneration: epidemiological evidence and challenges for future research. $\mathrm{Br} J \mathrm{Clin}$ Pharmacol 2013, 75:738-755.

13. Choi BY, Jang BG, Kim JH, Lee BE, Sohn M, Song HK, Suh SW: Prevention of traumatic brain injury-induced neuronal death by inhibition of NADPH oxidase activation. Brain Res 2012, 1481:49-58.

14. Asai T, Liu Y, Bae N, Nimer SD: The p53 tumor suppressor protein regulates hematopoietic stem cell fate. J Cell Physiol 2011, 226:2215-2221.

15. Xu J, Tian W, Ma X, Guo J, Shi Q, Jin Y, Xi J, Xu Z: The molecular mechanism underlying morphine-induced Akt activation: roles of protein phosphatases and reactive oxygen species. Cell Biochem Biophys 2011, 61:303-311.

16. Howes AL, Arthur JF, Zhang T, Miyamoto S, Adams JW, Dorn GW 2nd, Woodcock EA, Brown JH: Akt-mediated cardiomyocyte survival pathways are compromised by $\mathrm{G}$ alpha q-induced phosphoinositide 4,5-bisphosphate depletion. J Biol Chem 2003, 278:40343-40351.

17. Hou Q, Zhang D, Jarzylo L, Huganir RL, Man HY: Homeostatic regulation of AMPA receptor expression at single hippocampal synapses. Proc Natl Acad Sci U S A 2008, 105:775-780.

18. Damjanac M, Rioux Bilan A, Paccalin M, Pontcharraud R, Fauconneau B, Hugon J, Page G: Dissociation of Akt/PKB and ribosomal S6 kinase signaling markers in a transgenic mouse model of Alzheimer's disease. Neurobiol Dis 2008, 29:354-367.
19. De Gasperi R, Sosa MA, Dracheva S, Elder GA: Presenilin-1 regulates induction of hypoxia inducible factor-1a: altered activation by a mutation associated with familial Alzheimer's disease. Mol Neurodegener 2010, 5:38.

20. Uemura K, Kuzuya A, Shimozono Y, Aoyagi N, Ando K, Shimohama S, Kinoshita A: GSK3beta activity modifies the localization and function of presenilin 1. J Biol Chem 2007, 282:15823-15832.

21. Ryder J, Su Y, Ni B: Akt/GSK3beta serine/threonine kinases: evidence for a signalling pathway mediated by familial Alzheimer's disease mutations. Cell Signal 2004, 16:187-200.

22. Cheng B, Martinez AA, Morado J, Scofield V, Roberts JL, Maffi SK: Retinoic acid protects against proteasome inhibition associated cell death in $\mathrm{SH}$ SY5Y cells via the AKT pathway. Neurochem Int 2013, 62:31-42.

23. Haas-Kogan D, Stokoe D: PTEN in brain tumors. Expert Rev Neurother 2008 8:599-610.

24. Gupta A, Dey CS: PTEN, a widely known negative regulator of insulin/ $\mathrm{PI} 3 \mathrm{~K}$ signaling, positively regulates neuronal insulin resistance. $\mathrm{Mol} \mathrm{BiO} /$ Cell 2012, 23:3882-3898.

25. Nakamura N, Ramaswamy S, Vazquez F, Signoretti S, Loda M, Sellers WR: Forkhead transcription factors are critical effectors of cell death and cell cycle arrest downstream of PTEN. Mol Cell Biol 2000, 20:8969-8982.

26. Mulholland DJ, Dedhar S, Wu H, Nelson CC: PTEN and GSK3beta: key regulators of progression to androgen-independent prostate cancer. Oncogene 2006, 25:329-337.

27. Fournier MV, Fata JE, Martin KJ, Yaswen P, Bissell MJ: Interaction of Ecadherin and PTEN regulates morphogenesis and growth arrest in human mammary epithelial cells. Cancer Res 2009, 69:4545-4552.

28. Zhang H, Liu R, Wang R, Hong S, Xu H, Zhang YW: Presenilins regulate the cellular level of the tumor suppressor PTEN. Neurobiol Aging 2008, 29:653-660.

29. Rochet JC, Hay BA, Guo M: Molecular insights into Parkinson's disease. Prog Mol Biol Trans/ Sci 2012, 107:125-188.

30. Hajjar T, Meng GY, Rajion MA, Vidyadaran S, Othman F, Farjam AS, Li TA, Ebrahimi M: Omega 3 polyunsaturated fatty acid improves spatial learning and hippocampal peroxisome proliferator activated receptors (PPARa and PPARy) gene expression in rats. BMC Neurosci 2012, 13:109.

31. Yuan X, Zhang Z, Gong K, Zhao P, Qin J, Liu N: Inhibition of reactive oxygen species/extracellular signal-regulated kinases pathway by pioglitazone attenuates advanced glycation end products-induced proliferation of vascular smooth muscle cells in rats. Biol Pharm Bull 2011, 34:618-623

32. Chandra V, Huang P, Hamuro Y, Raghuram S, Wang Y, Burris TP, Rastinejad F: Structure of the intact PPAR-gamma-RXR- nuclear receptor complex on DNA. Nature 2008, 456:350-356.

33. Tarrade A, Rochette-Egly C, Guibourdenche J, Evain-Brion D: The expression of nuclear retinoid receptors in human implantation. Placenta 2000 21:703-710

34. Michalik L, Auwerx J, Berger JP, Chatterjee VK, Glass CK, Gonzalez FJ, Grimaldi PA, Kadowaki T, Lazar MA, O'Rahilly S, Palmer CN, Plutzky J, Reddy JK, Spiegelman BM, Staels B, Wahli W: International Union of Pharmacology. LXI. Peroxisome proliferator-activated receptors. Pharmacol Rev 2006, 58:726-741.

35. Yamanaka M, Ishikawa T, Griep A, Axt D, Kummer MP, Heneka MT: PPARy/ RXRa-induced and CD36-mediated microglial amyloid- $\beta$ phagocytosis results in cognitive improvement in amyloid precursor protein/presenilin 1 mice. J Neurosci 2012, 32:17321-17331.

36. Denner LA, Rodriguez-Rivera J, Haidacher SJ, Jahrling JB, Carmical JR, Hernandez CM, Zhao Y, Sadygov RG, Starkey JM, Spratt H, Luxon BA, Wood $T G$, Dineley KT: Cognitive enhancement with rosiglitazone links the hippocampal PPAR $y$ and ERK MAPK signaling pathways. J Neurosci 2012, 32:16725-16735a.

37. Cramer PE, Cirrito JR, Wesson DW, Lee CY, Karlo JC, Zinn AE, Casali BT, Restivo JL, Goebel WD, James MJ, Brunden KR, Wilson DA, Landreth GE: ApoE-directed therapeutics rapidly clear $\beta$-amyloid and reverse deficits in AD mouse models. Science 2012, 335:1503-1506.

38. Stiles BL, Kuralwalla-Martinez C, Guo W, Gregorian C, Wang Y, Tian J, Magnuson MA, Wu H: Selective deletion of Pten in pancreatic beta cells leads to increased islet mass and resistance to STZ-induced diabetes. Mol Cell Biol 2006, 26:2772-2781.

39. Gorbenko O, Panayotou G, Zhyvoloup A, Volkova D, Gout I, Filonenko V: Identification of novel PTEN-binding partners: PTEN interaction with fatty acid binding protein FABP4. Mol Cell Biochem 2010, 337:299-305. 
40. Tsuda M, Inoue-Narita T, Suzuki A, Itami S, Blumenberg M, Manabe M: Induction of gene encoding FABP4 in Pten-null keratinocytes. FEBS Lett 2009, 583:1319-1322.

41. Stiles B, Wang Y, Stahl A, Bassilian S, Lee WP, Kim YJ, Sherwin R, Devaskar S, Lesche R, Magnuson MA, Wu H: Liver-specific deletion of negative regulator Pten results in fatty liver and insulin hypersensitivity [corrected]. Proc Natl Acad Sci U S A 2004, 101:2082-2087.

42. Lecka-Czernik B: Aleglitazar, a dual PPARa and PPARy agonist for the potential oral treatment of type 2 diabetes mellitus. IDrugs 2010, 13:793-801.

43. Knobbe CB, Lapin V, Suzuki A, Mak TW: The roles of PTEN in development, physiology and tumorigenesis in mouse models: a tissue-by-tissue survey. Oncogene 2008, 27:5398-5415.

44. Yoshida H, Okumura N, Kitagishi Y, Nishimura Y, Matsuda S: Ethanol extract of rosemary repressed PTEN expression in K562 culture cells. Int J App/ Biol Pharm Technol 2011, 2:316-322.

45. Delgado-Esteban M, Martin-Zanca D, Andres-Martin L, Almeida A, Bolaños JP: Inhibition of PTEN by peroxynitrite activates the phosphoinositide-3kinase/Akt neuroprotective signaling pathway. J Neurochem 2007 102:194-205

46. Fuentealba RA, Liu Q, Kanekiyo T, Zhang J, Bu G: Low density lipoprotein receptor-related protein 1 promotes anti-apoptotic signaling in neuron by activating Akt survival pathway. J Biol Chem 2009, 284:34045-34053.

47. Chen LM, Xiong YS, Kong FL, Qu M, Wang Q, Chen XQ, Wang JZ, Zhu LQ: Neuroglobin attenuates Alzheimer-like tau hyperphosphorylation by activating Akt signaling. J Neurochem 2012, 120:157-164

48. Zhang C, Browne A, Child D, Tanzi RE: Curcumin decreases amyloid-beta peptide levels by attenuating the maturation of amyloid-beta precursor protein. J Biol Chem 2010, 285:28472-28480.

49. Sharma S, Ying Z, Gomez-Pinilla F: A pyrazole curcumin derivative restores membrane homeostasis disrupted after brain trauma. Exp Neurol 2010, 226:191-199.

50. Laird MD, Sukumari-Ramesh S, Swift AE, Meiler SE, Vender JR, Dhandapani $\mathrm{KM}$ : Curcumin attenuates cerebral edema following traumatic brain injury in mice: a possible role for aquaporin-4? J Neurochem 2010, 113:637-648.

51. Wu Q, Chen Y, Li X: HDAC1 expression and effect of curcumin on proliferation of Raji cells. J Huazhong Univ Sci Technolog Med Sci 2006, 26:199-201.

52. Wang R, Li YH, Xu Y, Li YB, Wu HL, Guo H, Zhang JZ, Zhang JJ, Pan XY, Li XJ: Curcumin produces neuroprotective effects via activating brain-derived neurotrophic factor/TrkB-dependent MAPK and PI-3K cascades in rodent cortical neurons. Prog Neuropsychopharmacol Biol Psychiatry 2010, 34:147-153.

53. Ma QL, Yang F, Rosario ER, Ubeda OJ, Beech W, Gant DJ, Chen PP, Hudspeth B, Chen C, Zhao Y, Vinters HV, Frautschy SA, Cole GM: Betaamyloid oligomers induce phosphorylation of tau and inactivation of insulin receptor substrate via c-Jun N-terminal kinase signaling: suppression by omega-3 fatty acids and curcumin. J Neurosci 2009, 29:9078-9089.

54. Yoshida H, Okumura N, Nishimura Y, Kitagishi Y, Matsuda S: Turmeric and curcumin suppress presenilin 1 protein expression in Jurkat cells. Exp Ther Med 2011, 2:629-632.

55. Kadish I, van Groen T: Lesion-induced hippocampal plasticity in transgenic Alzheimer's disease mouse models: influences of age, genotype, and estrogen. J Alzheimers Dis 2009, 18:429-445.

56. Liang C, Li H, Shen C, Lai J, Shi Z, Liu B, Tao HM: Genistein potentiates the anti-cancer effects of gemcitabine in human osteosarcoma via the downregulation of Akt and nuclear factor-kB pathway. Anticancer Agents Med Chem 2012, 12:554-563.

57. Villaflores $O B$, Chen YJ, Chen CP, Yeh JM, Wu TY: Curcuminoids and resveratrol as anti-Alzheimer agents. Taiwan J Obstet Gynecol 2012 51:515-525.

58. Huang TC, Lu KT, Wo YY, Wu YJ, Yang YL: Resveratrol protects rats from $A \beta$-induced neurotoxicity by the reduction of iNOS expression and lipid peroxidation. PLoS One 2011, 6:e29102.

59. Li F, Gong Q, Dong H, Shi J: Resveratrol, a neuroprotective supplement for Alzheimer's disease. Curr Pharm Des 2012, 18:27-33.

60. Karuppagounder SS, Pinto JT, Xu H, Chen HL, Beal MF, Gibson GE: Dietary supplementation with resveratrol reduces plaque pathology in a transgenic model of Alzheimer's disease. Neurochem Int 2009, 54:111-118.
61. Capiralla $H$, Vingtdeux $V$, Zhao $H$, Sankowski $R, A l$-Abed $Y$, Davies $P$, Marambaud P: Resveratrol mitigates lipopolysaccharide- and $A \beta-$ mediated microglial inflammation by inhibiting the TLR4/NF-KB/STAT signaling cascade. J Neurochem 2012, 120:461-472.

62. Kouroumichakis I, Papanas N, Zarogoulidis P, Liakopoulos V, Maltezos E, Mikhailidis DP: Fibrates: therapeutic potential for diabetic nephropathy? Eur J Intern Med 2012, 23:309-316.

63. Friedland SN, Leong A, Filion KB, Genest J, Lega IC, Mottillo S, Poirier P, Reoch J, Eisenberg MJ: The cardiovascular effects of peroxisome proliferator-activated receptor agonists. Am J Med 2012, 125:126-133.

64. Fu J, Zhang XW, Liu K, Li QS, Zhang LR, Yang XH, Zhang ZM, Li CZ, Luo Y, He ZX, Zhu HL: Hypolipidemic activity in Sprague-Dawley rats and constituents of a novel natural vegetable oil from Cornus wilsoniana fruits. Food Sci 2012, 77:H160-H169.

65. Donohue MC, Aisen PS: Mixed model of repeated measures versus slope models in Alzheimer's disease clinical trials. J Nutr Health Aging 2012, 16:360-364.

66. Shah R: The role of nutrition and diet in Alzheimer disease: a systematic review. J Am Med Dir Assoc 2013, 14:398-402.

67. Swanson D, Block R, Mousa SA: Omega-3 fatty acids EPA and DHA: health benefits throughout life. Adv Nutr 2012, 3:1-7.

68. Calon F: Omega-3 polyunsaturated fatty acids in Alzheimer's disease: key questions and partial answers. Curr Alzheimer Res 2011, 8:470-478.

69. Goncalves MB, Clarke E, Hobbs C, Malmqvist T, Deacon R, Jack J, Corcoran JP: Amyloid $\beta$ inhibits retinoic acid synthesis exacerbating Alzheimer disease pathology which can be attenuated by an retinoic acid receptor a agonist. Eur J Neurosci 2013, 37:1182-1192.

70. Lerner AJ, Gustaw-Rothenberg K, Smyth S, Casadesus G: Retinoids for treatment of Alzheimer's disease. Biofactors 2012, 38:84-89.

\subsection{6/alzrt208}

Cite this article as: Kitagishi and Matsuda: Diets involved in PPAR and $\mathrm{PI3K} / \mathrm{AKT} / \mathrm{PTEN}$ pathway may contribute to neuroprotection in a traumatic brain injury. Alzheimer's Research \& Therapy 2013, 5:42 